\title{
Knowledge and perceptions of antimicrobial stewardship concepts among final year pharmacy students in pharmacy schools across South Africa
}

\author{
a Department of Pharmacy, Sefako Makgatho Health Science University, Pretoria, South Africa \\ *Corresponding author, emails: Natalie.schellack@smu.ac.za, nschellack@gmail.com
}

Marisa Burger ${ }^{a}$, Jaco Fourie ${ }^{a}$, Devin Loots ${ }^{a}$, Tercia Mnisi ${ }^{a}$, Natalie Schellack ${ }^{a *}$, Selente Bezuidenhout ${ }^{a}$ and Johanna C Meyer ${ }^{a}$

Background: Antimicrobial stewardship is currently not mandatory as part of the undergraduate training of pharmacists. Identifying gaps in knowledge and a better understanding of pharmacy students' perceptions about antimicrobial stewardship could assist in recommendations for appropriate changes to the pharmacy degree curricula that may lead to more appropriate use of antimicrobials, within the multi-disciplinary team.

Methods: A descriptive quantitative study with a survey design was conducted at the eight universities offering the pharmacy degree in South Africa. An electronic questionnaire with four main categories on antimicrobial stewardship was administered to final (fourth) year pharmacy students (June-August 2015).

Results: An overall response rate of $26.6 \%(n=260)$ was obtained from 978 students, despite a weekly reminder. Most of the respondents were familiar with antimicrobial stewardship programmes in South Africa (71.9\%), and claimed to know what antimicrobial stewardship is (83.5\%) with significant differences between the universities $(p<0.001)$. Only $37.7 \%$ of the respondents recalled having had formal training on antimicrobial stewardship, with responses from the eight universities differing significantly $(p<0.001)$. However, almost all respondents $(98.5 \%)$ felt that a strong knowledge of antimicrobials was important for their future career, with $90.0 \%$ indicating that they would like more training on antimicrobial stewardship at undergraduate level.

Conclusion: There were significant differences between the eight universities with regards to undergraduate education on antimicrobial stewardship. In order to help prevent antimicrobial resistance, efforts should be made to introduce concepts of antimicrobial stewardship into the undergraduate pharmacy curricula to promote better use of antimicrobials and prevent antimicrobial resistance.

Keywords: antimicrobial resistance, antimicrobial stewardship, education, pharmacy students

\begin{abstract}
Introduction
Antimicrobial resistance is an increasingly important patient safety and public health issue. ${ }^{1,2}$ Emergence and spread of resistance is linked to antimicrobial exposure, both in the population and at an individual level. ${ }^{1}$ According to the World Health Organisation, antibacterial resistance surveillance has not been standardised, and techniques for data collection pertaining to resistance has not been refined. ${ }^{3}$ The common bacteria responsible for infections in both the hospital and community settings include Escherichia coli, Klebsiella pneumonia, Staphylococcus aureus, Streptococcus pneumonia, Enterococcus faecium, Acinetobacter baumannii, Enterobacter cloacae, nontyphoidal Salmonella, Shigella spp. and Neisseria gonorrhoea. ${ }^{3}$ Infections caused by resistant microorganisms often fail to respond to the standard treatment, resulting in prolonged illness and greater risk of death. ${ }^{1}$ An important key measure to prevent and reduce resistance is to use antimicrobial agents only when necessary and to use the shortest effective course. ${ }^{1}$ The timely selection and administration of appropriate antimicrobial therapy can significantly impact treatment outcomes, especially in patients with severe or life-threatening conditions. ${ }^{4}$ The recognised frequent misuse and overuse of antibiotics in hospitals and the impact on therapeutic efficacy, bacterial resistance and costs warrant the implementation of programmes that aim to improve the use of antibiotics in hospitals. ${ }^{5}$
\end{abstract}

Multiple studies have indicated that stewardship programmes aim to optimise individual patient outcomes whilst minimising unintended consequences, such as the generation of resistant organisms and untoward effects in the individual patient. ${ }^{1}$ These programmes typically involve evidence-based guidelines, educational programmes and regular feedback of antibiotic usage data to prescribers to promote rationale-based and evidence-based prescribing. ${ }^{1}$

The pharmacist's role in combating and preventing infectious diseases is essential, as antibiotic regimens become more complex due to the continuous evolving epidemiology of infections. Pharmacist-directed antimicrobial stewardship programmes have proliferated considerably over the past decade. ${ }^{4,6}$ The Minister of Health of South Africa launched the National Antimicrobial Resistance Strategy Framework published in 2015, calling on all healthcare providers to use antimicrobials appropriately. ${ }^{2}$ However, in South Africa there is little data on the content and effectiveness of the education of pharmacy students regarding antimicrobial stewardship. The purpose of this study was, therefore, to assess the knowledge and perceptions of fourth year pharmacy students in South Africa regarding antimicrobial stewardship concepts. The study further aimed to identify gaps in knowledge in order to provide appropriate recommendations for undergraduate pharmacy curricula that may lead to more appropriate use of antimicrobials in future practice.

\section{Method}

\section{Study design and population}

This was a quantitative descriptive survey. The target population for this study comprised all final (fourth) year pharmacy students registered at universities in South Africa. The universities offering 
Table 1: Response rate by university

\begin{tabular}{|c|c|c|c|}
\hline \multirow[t]{2}{*}{ University } & \multirow[t]{2}{*}{ Number of final year pharmacy students } & \multicolumn{2}{|c|}{ Response rate } \\
\hline & & Number $(n)$ & Percentage (\%) \\
\hline A & 241 & 14 & 5.8 \\
\hline B & 160 & 29 & 18.1 \\
\hline C & 75 & 22 & 29.3 \\
\hline$D$ & 126 & 23 & 18.3 \\
\hline$E$ & 103 & 11 & 10.7 \\
\hline $\mathrm{F}$ & 144 & 33 & 22.9 \\
\hline G & 69 & 69 & 100.0 \\
\hline H & 60 & 59 & 98.3 \\
\hline Overall & 978 & 260 & 26.6 \\
\hline
\end{tabular}

the degree in pharmacy are the University of Western Cape (UWC), Sefako Makgatho Health Sciences University (SMU) in collaboration with Tshwane University of Technology (TUT), University of KwaZulu-Natal (UKZN), Rhodes University (RU), Nelson Mandela Metropolitan University (NMMU), North West University (NWU), University of Limpopo (UL) and the University of the Witwatersrand (Johannesburg) (WITS). Inclusion criteria for student participation in the survey were the following: enrolled for the BPharm degree at the university; in the final year of study; willing to participate in the survey; and provide written informed consent.

\section{Data collection instrument and procedures}

An electronic questionnaire with response options was used to evaluate fourth year pharmacy students' (i) background knowledge and perceptions on antimicrobial stewardship; (ii) perceptions and attitudes about antimicrobial prescribing and resistance; (iii) knowledge of the goals, objectives and development strategies of antimicrobial stewardship; and, (iv) the quantity and perceived quality of education on antimicrobial stewardship. The questionnaire was adopted from a similar study done by Abbo et al. in 2013. ${ }^{7}$ The questionnaire was pretested for readability, length and relevance of the questions amongst five pharmacist interns from the Pharmacy Department at SMU, who had completed their undergraduate education in the previous year.

Data were collected using the electronic platform Typeform ${ }^{\mathrm{TM}}$. The questionnaire was made available online at each university's departmental student portal for a period of 12 weeks, from June 2015 to August 2015. A reminder email was sent on a weekly basis to a dedicated member of staff at the pharmacy department of each university, as a strategy to increase the response rate.

\section{Ethical considerations}

Ethical approval was obtained from the Sefako Makgatho University Research Ethics Committee (SMUREC/H/149/2015:UG). Permission to conduct the survey was obtained from the Head of the Pharmacy School at each of the universities. Participation was voluntary and responses were anonymous.

\section{Data analysis}

Data were entered onto Microsoft Excel ${ }^{\circ}$ spreadsheets and exported to IBM Statistical Analysis Software (SAS) for analysis. Prior to analysis, universities were de-identified and recoded as " $A$ ", “ $B$ ", “ $C$ ", “ $D$ ", “ $E$ ", “ $F$ ", " $G$ " and " $H$ ". Frequencies and percentages were calculated for all variables. The Fisher exact test or the ChiSquare test was used to test for differences in responses between the different universities. Statistical significance was set at $p \leq 0.05$.

\section{Results}

\section{Response rate}

Two hundred and sixty (26.6\%) of the 978 fourth year pharmacy students at the eight universities offering the pharmacy degree in South Africa completed the survey. The overall response rate was $26.6 \%$, ranging from $5.8 \%$ to $100.0 \%$. Response rates by institution are shown in Table 1.

\section{Student demographics}

Overall, $66.2 \%$ of the respondents were female. Nearly two-thirds $(65.0 \%)$ of the students were between the ages of 22 and 25 years, $15.8 \%$ were younger than 22 years and $19.2 \%$ were over the age of 25 years.

\section{Background knowledge and perceptions on antimicrobial stewardship}

Respondents' background knowledge and perceptions on antimicrobial stewardship is summarised in Table 2. Most of the students (83.5\%) indicated that they know what antimicrobial stewardship is and that they were familiar with antimicrobial stewardship programmes in South Africa (71.9\%), with significant differences between the universities $(p<0.001)$.

The vast majority (95.8\%) of respondents indicated that implementation of antimicrobial stewardship programmes are essential in South Africa. Only $24.6 \%$ of respondents reported that prescribing and use of antimicrobials are actually appropriate in South Africa, with university responses ranging from $6.1 \%$ to $40.7 \%(p<0.001)$. Most respondents agreed that antimicrobial stewardship involves the appropriate selection of antibiotics (95.0\%), the appropriate dosing and selection of route of administration (86.5\%), and the appropriate duration of therapy $(88.8 \%)$, while only half of them $(50.4 \%)$ indicated that the study of antibiotics is also a part of antimicrobial stewardship.

\section{Perceptions and attitudes about antimicrobial prescribing and resistance}

Respondents' perceptions and attitudes about antimicrobial prescribing and resistance are summarised in Table 3 . The majority $(97.7 \%)$ of respondents agreed that antimicrobial resistance is a worldwide problem. According to most of the respondents, the promotion of antimicrobial resistance is attributed to the widespread and overuse of antimicrobials (94.2\%), poor patient adherence to medication (89.5\%), and the 
Table 2: Background knowledge and perceptions of final year pharmacy students on antimicrobial stewardship

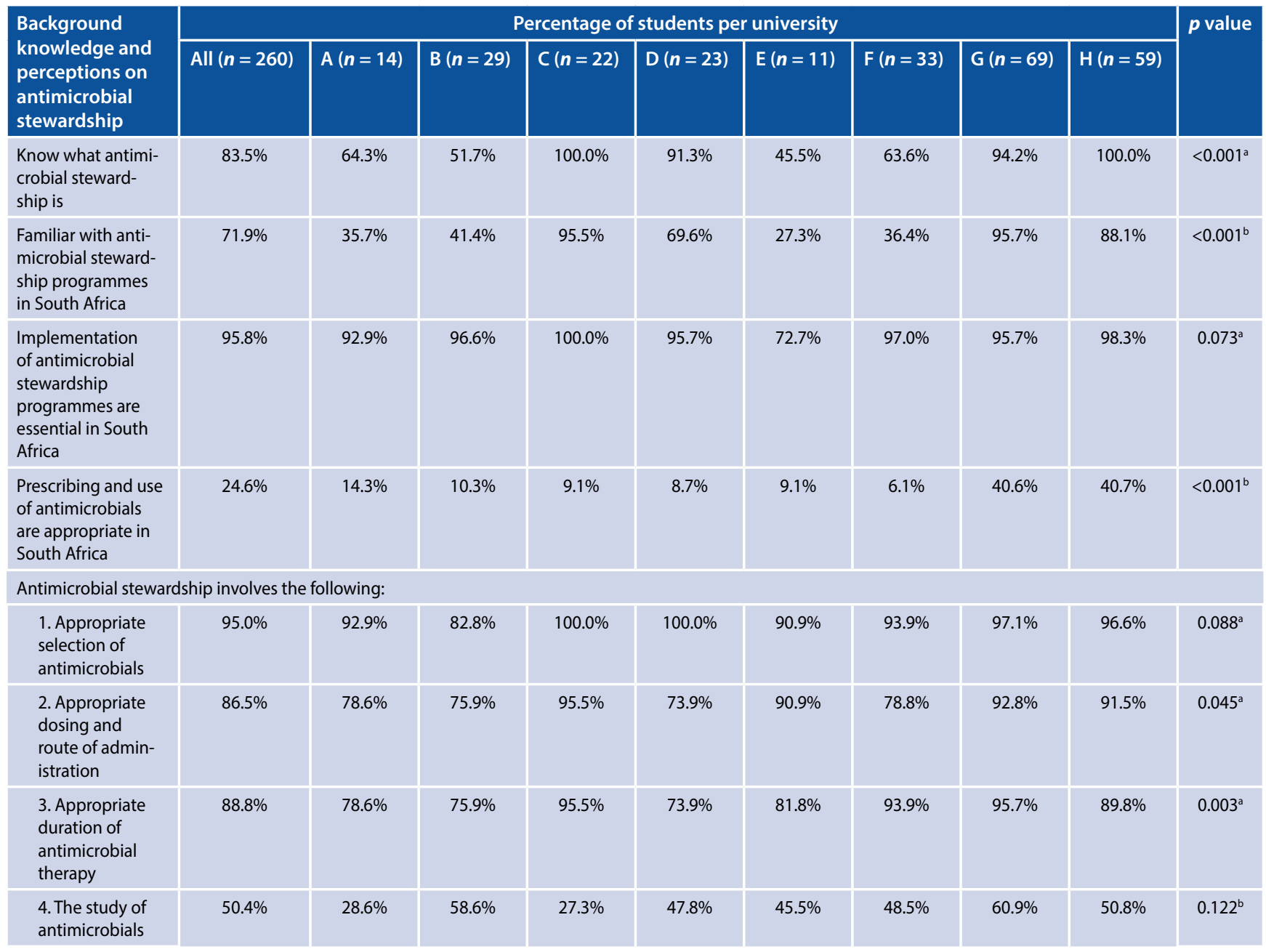

aFisher exact test.

${ }^{\mathrm{b}} \mathrm{Chi}$-Square test.

use of broad spectrum antibiotics when narrow spectrum is available (84.2\%). Nearly half of the respondents (48.8\%) perceived that the substandard quality of antimicrobials promotes resistance, with significant differences in the responses from the individual universities ( $p=0.007)$. Only a third $(33.8 \%)$ of all respondents perceived that poor handwashing practice was a contributing factor to antimicrobial resistance.

The majority of respondents (98.5\%) indicated that better use of antimicrobials will reduce problems with resistance. In terms of interventions that can be used to combat antimicrobial resistance, responses from the universities in most cases differed significantly, except in the case of the development of institutional guidelines for antimicrobial use, as indicated by $86.2 \%$ of respondents. Overall, $92.3 \%$ of the respondents indicated education on antimicrobial therapy, whether for fellow healthcare workers or patients, would combat resistance; while, two-thirds (65.8\%) of the respondents reported that a reduction in antimicrobial usage would combat resistance.

Most of the respondents (98.1\%) agreed that inappropriate use of antimicrobials can harm patients. Nearly all of the respondents (98.5\%) felt that a strong knowledge of antimicrobials is important in their careers. The students were asked to identify bacteria that are currently the most problematic with regards to resistance (Table 3), 12.3\% reported the virus Herpes simplex and
$13.5 \%$ reported the virus Influenza $A$ as bacteria, with significant differences between the universities for the latter $(p=0.006)$. The vast majority of students indicated that they would like to have more education on the appropriate use of antimicrobials (96.5\%) and on antimicrobial resistance $(93.1 \%)$, with no significant differences amongst the universities for the last-mentioned.

\section{Antimicrobial stewardship goals, objectives and development strategies}

Final year pharmacy students' responses regarding the goals of antimicrobial stewardship, objectives and development strategies are summarised in Table 4 . The majority of students agreed that the goals of antimicrobial stewardship seek to reduce antimicrobial resistance $(98.5 \%)$. There was also agreement that additional goals were to reduce the hospital stay (72.7\%), and minimise toxicity and other adverse effects (83.1\%), although with significant differences in the responses from the different universities $(p<0.001)$.

Overall, $95.0 \%$ of respondents felt that clinical and hospital pharmacists should be part of the antimicrobial stewardship team, and $83.8 \%$ were of opinion that it is one of the responsibilities of the clinical pharmacist to assemble and lead the core antimicrobial stewardship team. Infectious disease physicians and infection-control staff should be included in the team, as reported by $91.9 \%$ and $81.5 \%$ respondents, respectively. 
Table 3: Perceptions and attitudes of final year pharmacy students about antimicrobial prescribing and resistance

\begin{tabular}{|c|c|c|c|c|c|c|c|c|c|c|}
\hline \multirow{2}{*}{$\begin{array}{l}\text { Perceptions and } \\
\text { attitudes about } \\
\text { antimicrobial prescribing } \\
\text { and resistance }\end{array}$} & \multicolumn{9}{|c|}{ Percentage of students per university } & \multirow[t]{2}{*}{$p$ value } \\
\hline & All $(n=260)$ & $A(n=14)$ & $B(n=29)$ & $C(n=22)$ & $D(n=23)$ & $E(n=11)$ & $F(n=33)$ & G $(n=69)$ & $H(n=59)$ & \\
\hline $\begin{array}{l}\text { Antimicrobial resistance is a } \\
\text { worldwide problem }\end{array}$ & $97.7 \%$ & $100.0 \%$ & $93.1 \%$ & $95.5 \%$ & $100.0 \%$ & $100.0 \%$ & $93.9 \%$ & $100.0 \%$ & $98.3 \%$ & $0.211^{\mathrm{a}}$ \\
\hline \multicolumn{11}{|c|}{ Antimicrobial resistance is promoted by: } \\
\hline $\begin{array}{l}\text { 1. Widespread/overuse of } \\
\text { antimicrobials }\end{array}$ & $94.2 \%$ & $85.7 \%$ & $89.7 \%$ & $100.0 \%$ & $100.0 \%$ & $90.9 \%$ & $90.9 \%$ & $94.2 \%$ & $96.6 \%$ & $0.298^{\mathrm{a}}$ \\
\hline $\begin{array}{l}\text { 2. Use of broad spectrum } \\
\text { antimicrobials when nar- } \\
\text { row spectrum is available }\end{array}$ & $84.2 \%$ & $85.7 \%$ & $79.3 \%$ & $66.7 \%$ & $73.9 \%$ & $90.9 \%$ & $66.7 \%$ & $91.3 \%$ & $88.1 \%$ & $0.053^{\mathrm{a}}$ \\
\hline $\begin{array}{l}\text { 3. Poor hand washing } \\
\text { practice }\end{array}$ & $33.8 \%$ & $21.4 \%$ & $31.0 \%$ & $54.5 \%$ & $21.6 \%$ & $18.2 \%$ & $30.3 \%$ & $33.3 \%$ & $39.0 \%$ & $0.334^{b}$ \\
\hline $\begin{array}{l}\text { 4. Poor patient adherence } \\
\text { to medication }\end{array}$ & $89.5 \%$ & $78.6 \%$ & $82.8 \%$ & $100.0 \%$ & $87.0 \%$ & $81.8 \%$ & $90.9 \%$ & $89.9 \%$ & $93.2 \%$ & $0.258^{\mathrm{a}}$ \\
\hline $\begin{array}{l}\text { 5. Substandard quality of } \\
\text { antimicrobials }\end{array}$ & $48.8 \%$ & $35.7 \%$ & $31.0 \%$ & $40.9 \%$ & $47.8 \%$ & $63.6 \%$ & $30.3 \%$ & $66.7 \%$ & $50.8 \%$ & $0.007^{b}$ \\
\hline $\begin{array}{l}\text { Better use of antimicrobials } \\
\text { will reduce problems with } \\
\text { antimicrobial resistance }\end{array}$ & $98.5 \%$ & $92.9 \%$ & $96.6 \%$ & $100.0 \%$ & $95.7 \%$ & $100.0 \%$ & $100.0 \%$ & $98.6 \%$ & $100.0 \%$ & $0.271^{\mathrm{a}}$ \\
\hline \multicolumn{11}{|c|}{ Interventions that can possibly combat antimicrobial resistance: } \\
\hline $\begin{array}{l}\text { 1. Antimicrobial usage } \\
\text { policies }\end{array}$ & $86.9 \%$ & $64.3 \%$ & $65.5 \%$ & $90.9 \%$ & $78.3 \%$ & $63.6 \%$ & $93.9 \%$ & $92.8 \%$ & $98.3 \%$ & $<0.001^{\mathrm{a}}$ \\
\hline $\begin{array}{l}\text { 2. Reduction of antibiotic } \\
\text { use }\end{array}$ & $65.8 \%$ & $85.7 \%$ & $37.9 \%$ & $77.3 \%$ & $47.8 \%$ & $81.8 \%$ & $57.6 \%$ & $78.3 \%$ & $64.4 \%$ & $0.001^{b}$ \\
\hline $\begin{array}{l}\text { 3. Establish national } \\
\text { antimicrobial resistance } \\
\text { surveillance }\end{array}$ & $79.6 \%$ & $28.6 \%$ & $55.2 \%$ & $90.9 \%$ & $87.0 \%$ & $72.7 \%$ & $75.8 \%$ & $89.9 \%$ & $88.1 \%$ & $<0.001^{\mathrm{a}}$ \\
\hline $\begin{array}{l}\text { 4. Development of } \\
\text { institutional guidelines for } \\
\text { antimicrobial use }\end{array}$ & $86.2 \%$ & $78.6 \%$ & $79.3 \%$ & $90.9 \%$ & $78.3 \%$ & $100.0 \%$ & $81.8 \%$ & $92.8 \%$ & $84.7 \%$ & $0.257^{a}$ \\
\hline $\begin{array}{l}\text { 5. Education on antimicro- } \\
\text { bial therapy }\end{array}$ & $92.3 \%$ & $64.3 \%$ & $86.2 \%$ & $95.5 \%$ & $91.3 \%$ & $90.9 \%$ & $90.9 \%$ & $97.1 \%$ & $96.6 \%$ & $0.009^{a}$ \\
\hline $\begin{array}{l}\text { Inappropriate use of antimi- } \\
\text { crobials can harm patients }\end{array}$ & $98.1 \%$ & $92.9 \%$ & $100.0 \%$ & $100.0 \%$ & $95.7 \%$ & $100.0 \%$ & $100.0 \%$ & $100.0 \%$ & $94.9 \%$ & $0.166^{\mathrm{b}}$ \\
\hline $\begin{array}{l}\text { Strong knowledge of anti- } \\
\text { microbials is important for } \\
\text { future career }\end{array}$ & $98.5 \%$ & $100.0 \%$ & $96.6 \%$ & $100.0 \%$ & $100.0 \%$ & $100.0 \%$ & $100.0 \%$ & $97.1 \%$ & $98.3 \%$ & $0.975^{\mathrm{a}}$ \\
\hline $\begin{array}{l}\text { Would like more education } \\
\text { on appropriate use of antimi- } \\
\text { crobials }\end{array}$ & $96.5 \%$ & $85.7 \%$ & $96.6 \%$ & $95.5 \%$ & $95.7 \%$ & $90.9 \%$ & $100.0 \%$ & $100.0 \%$ & $94.9 \%$ & $0.028^{b}$ \\
\hline $\begin{array}{l}\text { Would like more education } \\
\text { on antimicrobial resistance }\end{array}$ & $93.1 \%$ & $78.6 \%$ & $100.0 \%$ & $86.4 \%$ & $91.3 \%$ & $100.0 \%$ & $90.9 \%$ & $98.6 \%$ & $89.8 \%$ & $0.085^{\mathrm{a}}$ \\
\hline \multicolumn{11}{|c|}{ Most troublesome microorganism: } \\
\hline 1. Enterococcus faecium & $45.0 \%$ & $42.9 \%$ & $34.5 \%$ & $63.6 \%$ & $43.5 \%$ & $18.2 \%$ & $21.2 \%$ & $69.6 \%$ & $33.9 \%$ & $<0.001^{b}$ \\
\hline 2. Herpes simplex & $12.3 \%$ & $7.1 \%$ & $20.7 \%$ & $0.0 \%$ & $17.4 \%$ & $9.1 \%$ & $18.2 \%$ & $7.2 \%$ & $15.3 \%$ & $0.183^{\mathrm{a}}$ \\
\hline 3. Staphylococcus aureus & $81.9 \%$ & $100.0 \%$ & $69.0 \%$ & $90.9 \%$ & $87.0 \%$ & $90.9 \%$ & $87.9 \%$ & $92.8 \%$ & $61.0 \%$ & $<0.001^{\mathrm{a}}$ \\
\hline 4. Klebsiella pneumoniae & $55.4 \%$ & $64.3 \%$ & $41.4 \%$ & $63.6 \%$ & $65.2 \%$ & $63.6 \%$ & $45.5 \%$ & $65.2 \%$ & $45.8 \%$ & $0.148^{b}$ \\
\hline 5. Influenza A & $13.5 \%$ & $7.1 \%$ & $20.7 \%$ & $0.0 \%$ & $13.0 \%$ & $9.1 \%$ & $27.3 \%$ & $4.3 \%$ & $20.3 \%$ & $0.006^{\mathrm{a}}$ \\
\hline 6. Acinetobacter baumannii & $44.2 \%$ & $50.0 \%$ & $24.1 \%$ & $31.8 \%$ & $30.4 \%$ & $9.1 \%$ & $15.2 \%$ & $92.8 \%$ & $28.8 \%$ & $<0.001^{b}$ \\
\hline 7. Pseudomonas aeruginosa & $66.9 \%$ & $78.6 \%$ & $79.3 \%$ & $72.7 \%$ & $87.0 \%$ & $72.7 \%$ & $66.7 \%$ & $50.7 \%$ & $66.1 \%$ & $0.028^{b}$ \\
\hline
\end{tabular}

\section{aFisher exact test.}

${ }^{\mathrm{b}} \mathrm{Chi}$-Square test.

The majority of respondents felt that promoting optimal use of antimicrobial agents (92.3\%) and education of other health care professionals $(91.5 \%)$ is part of the role of the pharmacist in antimicrobial stewardship. Very few of the students (7.3\%; 19 respondents from five universities) reported that prescribing antimicrobial agents to patients over the counter is part of the role of the pharmacist. 
Table 4: Final year pharmacy students' knowledge of antimicrobial stewardship goals, objectives and development strategies

\begin{tabular}{|c|c|c|c|c|c|c|c|c|c|c|}
\hline \multirow{2}{*}{$\begin{array}{l}\text { Antimicrobial stewardship } \\
\text { goals, objectives and } \\
\text { development strategies }\end{array}$} & \multicolumn{9}{|c|}{ Percentage of students per university } & \multirow[t]{2}{*}{$p$ value } \\
\hline & All $(n=260)$ & $A(n=14)$ & $B(n=29)$ & $C(n=22)$ & $D(n=23)$ & $E(n=11)$ & $F(n=33)$ & G $(n=69)$ & $H(n=59)$ & \\
\hline \multicolumn{11}{|c|}{ Goals of antimicrobial stewardship seek to achieve: } \\
\hline 1. Increasing antimicrobial use & $6.2 \%$ & $0.0 \%$ & $3.4 \%$ & $9.1 \%$ & $0.0 \%$ & $0.0 \%$ & $9.1 \%$ & $0.0 \%$ & $16.9 \%$ & $0.004^{a}$ \\
\hline 2. Reducing hospital stay & $72.7 \%$ & $28.6 \%$ & $55.2 \%$ & $86.4 \%$ & $56.5 \%$ & $72.7 \%$ & $54.5 \%$ & $81.2 \%$ & $93.2 \%$ & $<0.001^{\mathrm{b}}$ \\
\hline $\begin{array}{l}\text { 3. Increasing duration of } \\
\text { therapy to ensure therapeutic } \\
\text { efficacy }\end{array}$ & $10.4 \%$ & $0.0 \%$ & $10.3 \%$ & $0.0 \%$ & $4.3 \%$ & $9.1 \%$ & $9.1 \%$ & $11.6 \%$ & $18.6 \%$ & $0.265^{a}$ \\
\hline $\begin{array}{l}\text { 4. Increasing use of broad } \\
\text { spectrum antibiotics }\end{array}$ & $7.7 \%$ & $0.0 \%$ & $3.4 \%$ & $0.0 \%$ & $4.3 \%$ & $0.0 \%$ & $12.1 \%$ & $8.7 \%$ & $13.6 \%$ & $0.408^{a}$ \\
\hline $\begin{array}{l}\text { 5. Reducing antimicrobial } \\
\text { resistance }\end{array}$ & $98.5 \%$ & $100.0 \%$ & $96.6 \%$ & $100.0 \%$ & $100.0 \%$ & $100.0 \%$ & $100.0 \%$ & $100.0 \%$ & $94.9 \%$ & $0.391^{\mathrm{a}}$ \\
\hline $\begin{array}{l}\text { 6. Minimising toxicity and } \\
\text { other adverse effects }\end{array}$ & $83.1 \%$ & $57.1 \%$ & $72.4 \%$ & $77.3 \%$ & $69.6 \%$ & $90.9 \%$ & $72.7 \%$ & $92.8 \%$ & $94.9 \%$ & $<0.001^{\mathrm{a}}$ \\
\hline $\begin{array}{l}\text { Assembling and leading of the } \\
\text { core team is one of the responsi- } \\
\text { bilities of the clinical pharmacist }\end{array}$ & $83.8 \%$ & $85.7 \%$ & $82.8 \%$ & $90.9 \%$ & $73.9 \%$ & $90.9 \%$ & $72.7 \%$ & $81.2 \%$ & $93.2 \%$ & $0.167^{a}$ \\
\hline \multicolumn{11}{|c|}{ Members of the antimicrobial stewardship team include: } \\
\hline $\begin{array}{l}\text { 1. Infectious disease physi- } \\
\text { cians }\end{array}$ & $91.9 \%$ & $92.9 \%$ & $86.2 \%$ & $95.5 \%$ & $87.0 \%$ & $90.9 \%$ & $90.9 \%$ & $95.7 \%$ & $91.5 \%$ & $0.711^{\mathrm{a}}$ \\
\hline 2. Occupational therapists & $20.8 \%$ & $7.1 \%$ & $13.8 \%$ & $9.1 \%$ & $26.1 \%$ & $9.1 \%$ & $9.1 \%$ & $33.3 \%$ & $23.7 \%$ & $0.044^{\mathrm{a}}$ \\
\hline $\begin{array}{l}\text { 3. Clinical and hospital phar- } \\
\text { macists }\end{array}$ & $95.0 \%$ & $92.9 \%$ & $96.6 \%$ & $100.0 \%$ & $95.7 \%$ & $90.9 \%$ & $97.0 \%$ & $94.2 \%$ & $93.2 \%$ & $0.904^{\mathrm{a}}$ \\
\hline 4. Infection control staff & $81.5 \%$ & $64.3 \%$ & $79.3 \%$ & $77.3 \%$ & $78.3 \%$ & $63.6 \%$ & $81.8 \%$ & $87.0 \%$ & $86.4 \%$ & $0.298^{\mathrm{a}}$ \\
\hline 5. Hospital cleaning staff & $37.7 \%$ & $35.7 \%$ & $48.3 \%$ & $18.2 \%$ & $43.5 \%$ & $9.1 \%$ & $33.3 \%$ & $49.3 \%$ & $32.2 \%$ & $0.050^{b}$ \\
\hline \multicolumn{11}{|c|}{ The role of the pharmacist in antimicrobial stewardship: } \\
\hline $\begin{array}{l}\text { 1. Promote optimal use of } \\
\text { antimicrobial agents }\end{array}$ & $92.3 \%$ & $85.7 \%$ & $96.6 \%$ & $95.5 \%$ & $87.0 \%$ & $100.0 \%$ & $90.9 \%$ & $89.9 \%$ & $94.9 \%$ & $0.692^{\mathrm{a}}$ \\
\hline $\begin{array}{l}\text { 2. Prescribe antimicrobial } \\
\text { agents over-the-counter }\end{array}$ & $7.3 \%$ & $14.3 \%$ & $0.0 \%$ & $0.0 \%$ & $4.3 \%$ & $9.1 \%$ & $15.2 \%$ & $0.0 \%$ & $16.9 \%$ & $<0.001^{a}$ \\
\hline $\begin{array}{l}\text { 3. Educate health care pro- } \\
\text { fessionals }\end{array}$ & $91.5 \%$ & $78.6 \%$ & $89.7 \%$ & $100.0 \%$ & $78.3 \%$ & $72.7 \%$ & $93.9 \%$ & $94.2 \%$ & $96.6 \%$ & $0.074^{\mathrm{a}}$ \\
\hline $\begin{array}{l}\text { 4. Work with therapeutic com- } \\
\text { mittees to develop policies }\end{array}$ & $88.5 \%$ & $78.6 \%$ & $75.9 \%$ & $90.9 \%$ & $87.0 \%$ & $90.9 \%$ & $84.8 \%$ & $97.1 \%$ & $88.1 \%$ & $0.055^{\mathrm{a}}$ \\
\hline
\end{tabular}

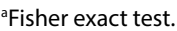

${ }^{b} \mathrm{Chi}$-Square test.

\section{Education on antimicrobial stewardship}

Perceptions of final year pharmacy students regarding the quantity and quality of education on antimicrobial stewardship at undergraduate level are summarised in Table 5. With reference to their pharmacy curricula, only 98 of the 260 respondents (37.7\%) recalled having had formal training on antimicrobial stewardship, with significant differences in responses from the various universities $(p<0.001)$. The majority of respondents (90.0\%) indicated that they would like more training on antimicrobial stewardship. There was a significant difference $(p<0.001)$ amongst the universities in terms of how respondents rated their knowledge on antimicrobial stewardship, with half of them (51.9\%) rating it as average and $11.9 \%$ as poor.

\section{Discussion}

This study evaluated pharmacy students' knowledge and perceptions on antimicrobial stewardship and antimicrobial resistance. To the best of our knowledge, this study is the first to assess these aspects amongst pharmacy students in South Africa. The response rate for this study was relatively low, despite continued efforts over the 12 week study period to obtain a better response rate. This low response rate from the students at the different universities is not unique to this particular study and similar trends have been observed in other settings. ${ }^{8}$

We found that although the majority of respondents were familiar with antimicrobial stewardship programmes in South Africa there were significant differences in the responses between the eight universities. Similar results were observed in a study conducted by Cotta and colleagues in 2014, ${ }^{9}$ in which $80.0 \%$ of the pharmacists had heard about antimicrobial stewardship. Only $24.6 \%$ of the respondents felt that prescribing and use of antimicrobials are appropriate in South Africa, with significant differences in the responses between the universities. These results concur with those reported by Abera in 2014, ${ }^{10}$ to the effect that one of the three leading causes of antimicrobial resistance is overuse and frequent prescribing of broad-spectrum antibiotics.

Results showed that the most important interventions to combat antimicrobial resistance are considered to be education on antimicrobial therapy, development of antimicrobial usage policies and the development of institutional guidelines for antimicrobial use. In this study, the majority of the respondents 
Table 5: Perceptions of final year pharmacy students on the quantity and quality of education on antimicrobial stewardship

\begin{tabular}{|c|c|c|c|c|c|c|c|c|c|c|}
\hline \multirow{2}{*}{$\begin{array}{l}\text { Quantity and } \\
\text { quality of } \\
\text { education on } \\
\text { antimicrobial } \\
\text { stewardship }\end{array}$} & \multicolumn{9}{|c|}{ Percentage of students per university } & \multirow[t]{2}{*}{$p$ value } \\
\hline & All $(n=260)$ & $A(n=14)$ & B $(n=29)$ & $C(n=22)$ & $\mathrm{D}(n=23)$ & $E(n=11)$ & $\mathrm{F}(n=33)$ & G $(n=69)$ & $\mathrm{H}(n=59)$ & \\
\hline $\begin{array}{l}\text { Had formal } \\
\text { training on } \\
\text { antimicrobial } \\
\text { stewardship }\end{array}$ & $37.7 \%$ & $28.6 \%$ & $20.7 \%$ & $54.5 \%$ & $13.0 \%$ & $27.3 \%$ & $21.2 \%$ & $39.1 \%$ & $61.0 \%$ & $<0.001^{\mathrm{b}}$ \\
\hline \multicolumn{11}{|c|}{ Hours of training received on antimicrobial stewardship: } \\
\hline $1.1-4$ & $27.7 \%$ & $0.0 \%$ & $3.4 \%$ & $40.9 \%$ & $13.0 \%$ & $9.1 \%$ & $6.1 \%$ & $42.0 \%$ & $47.5 \%$ & $<0.001^{b}$ \\
\hline $2.5-7$ & $3.8 \%$ & $7.1 \%$ & $3.4 \%$ & $9.1 \%$ & $4.3 \%$ & $0.0 \%$ & $0.0 \%$ & $2.9 \%$ & $5.1 \%$ & $<0.001^{b}$ \\
\hline $\begin{array}{l}\text { 3. More } \\
\text { than } 8\end{array}$ & $6.2 \%$ & $14.3 \%$ & $0.0 \%$ & $9.1 \%$ & $17.4 \%$ & $0.0 \%$ & $3.0 \%$ & $1.4 \%$ & $10.2 \%$ & $<0.001^{\mathrm{b}}$ \\
\hline 4. No training & $61.9 \%$ & $78.6 \%$ & $93.1 \%$ & $40.9 \%$ & $65.2 \%$ & $90.9 \%$ & $90.9 \%$ & $53.6 \%$ & $37.3 \%$ & $<0.001^{\mathrm{b}}$ \\
\hline $\begin{array}{l}\text { Would like more } \\
\text { training on } \\
\text { antimicrobial } \\
\text { stewardship }\end{array}$ & $90.0 \%$ & $78.6 \%$ & $96.6 \%$ & $86.4 \%$ & $82.6 \%$ & $90.9 \%$ & $97.0 \%$ & $98.6 \%$ & $79.7 \%$ & $0.007^{a}$ \\
\hline \multicolumn{11}{|c|}{ Rating of knowledge on antimicrobial stewardship: } \\
\hline 1. Poor & $11.9 \%$ & $28.6 \%$ & $34.5 \%$ & $0.0 \%$ & $4.3 \%$ & $9.1 \%$ & $36.4 \%$ & $0.0 \%$ & $5.1 \%$ & $<0.001^{b}$ \\
\hline 2. Average & $51.9 \%$ & $50.0 \%$ & $48.3 \%$ & $50.0 \%$ & $69.6 \%$ & $54.5 \%$ & $51.5 \%$ & $42.0 \%$ & $59.3 \%$ & $<0.001^{b}$ \\
\hline 3. Good & $31.5 \%$ & $14.3 \%$ & $17.2 \%$ & $27.3 \%$ & $21.7 \%$ & $36.4 \%$ & $12.1 \%$ & $53.6 \%$ & $32.2 \%$ & $<0.001^{b}$ \\
\hline 4. Very good & $4.6 \%$ & $7.1 \%$ & $0.0 \%$ & $22.7 \%$ & $4.3 \%$ & $0.0 \%$ & $0.0 \%$ & $4.3 \%$ & $3.4 \%$ & $<0.001^{b}$ \\
\hline
\end{tabular}

aFisher exact test.

${ }^{\mathrm{b}} \mathrm{Chi}$-Square test.

across the different universities shared the common perception that antimicrobial resistance is a worldwide problem, which is consistent with the findings of studies conducted elsewhere. ${ }^{9,10}$

The three leading causes of antimicrobial resistance were widespread and overuse of antimicrobials, use of broadspectrum antimicrobials when narrow spectrum is available and poor patient adherence to prescribed antimicrobials. This is consistent with studies conducted in Australia, Ethiopia, Scotland, France and Spain which reported that too many broadspectrum antimicrobials, too many antimicrobial prescriptions, and inappropriate duration of therapy were leading causes of antimicrobial resistance..$^{9,11,12}$

Although most respondents were familiar with antimicrobial stewardship goals, objectives and development strategies, we found significant differences in the responses between the universities for certain aspects. When questioned on what they thought the role of the pharmacist is in antimicrobial stewardship, a few respondents reported prescribing of antimicrobials over the counter, with significant differences in the responses between the universities. However, in terms of legislation, according to the Good Pharmacy Practice rules of the South African Pharmacy Council, and the Medicines and Related Substances Act (Act 101 of 1965), a pharmacist is not allowed to sell Schedule 4 medication, which includes antimicrobials, over-the-counter without a prescription. ${ }^{13,14}$ Although some respondents felt that over-the-counter prescribing by a pharmacist is correct and one of the roles of the pharmacist, the majority of students felt promoting optimal use and education on the use of antibiotics are very important tasks a pharmacist can perform to aid in the prevention of antimicrobial resistance.
The study also identified significant differences in the responses between the universities with regards to education on antimicrobial stewardship. This was evident when respondents were asked to state the number of hours of training on antimicrobial stewardship received. Almost all of the respondents wanted more education on antimicrobial stewardship. Similar results were reported from a study on antimicrobial training, conducted amongst medical students at a medical school in the United States of America. ${ }^{15}$

Strengths of our study were that the survey was anonymous and voluntary, which likely reduced the tendency of the respondents to provide "socially desired" answers. The study was conducted in the final year of undergraduate study when students had completed their formal academic curriculum, thus providing a better estimate of their education almost upon graduation. A limitation to the study was the low response rates from most of the universities.

\section{Conclusion}

Our study has demonstrated that final year pharmacy students across all the universities share similar perceptions and attitudes in terms of antimicrobial stewardship. Differences in the extent of undergraduate training on this topic provided by the various pharmacy schools were evident. The results of this survey draw attention to this important educational gap, and efforts should be made to address these gaps during the undergraduate training of pharmacists. Our results, therefore, suggest that pharmacy students should be the target of teaching on antimicrobial usage, antimicrobial resistance and the principles of antimicrobial stewardship. However, it is important for all healthcare professionals to work together as a team to combat the increasing problem of resistance. 
Acknowledgements - The authors thank the students for their participation, as well as staff from the universities for their patience and cooperation. We would like to thank Prof $\mathrm{H}$ Schoeman for his expertise and assistance with the statistical analysis of the data. Sefako Makgatho Health Sciences University is acknowledged for financial assistance and administrative support provided.

Conflict of interest - The authors do not have any commercial interest or association that may pose a conflict of interest

\section{References}

1. Wickens HJ, Farrell S, Ashiru-Oredope DAl, et al. The increasing role of pharmacists in antimicrobial stewardship in English hospitals. J Antimicrob Chemother. 2013;68(11):2675-81.

2. National Department of Health (NDOH). Antimicrobial Resistance National Strategy Framework 2014-2024. Pretoria: NDOH, 2015 [cited 2016 Mar 1]. Available from: http://www.nda.agric.za/docs/media/ A5\%20Antimicrobial\%20Resistance\%20National\%20Strategy $\% 20$ Framework\%202014-2024_final.pdf.

3. World Health Organization (WHO). Antimicrobial resistance: global report on surveillance. 2014 [cited 2016 Mar 1]. Available from: http:// www.who.int/drugresistance/documents/surveillancereport/en/.

4. Drew RH. Antimicrobial stewardship programs: how to start and steer a successful program. J Manage Care Pharm. 2009;15(2 Supp A):18-23.

5. Pasquale TR, Komorny KM, Letting-Mangira $D$, et al. A pharmacistphysician antibiotic support team. Pharmacol Ther. 2004;29(1):33-40.

6. McCoy D, Toussaint K, Gallagher JC. The pharmacist's role in preventing antibiotic resistance. US Pharmacist. 2011 [cited 2016 Mar 1];36(7):42-9. Available from: http://www.medscape.com/ viewarticle/747212.

7. Abbo LM, Cosgrove SE, Pottinger PS, et al. Medical students' perceptions and knowledge about antimicrobial stewardship: how are we educating our future prescribers? Clin Infect Dis. 2013 [cited 2016 Mar 1];57(5):631-638. doi: 10.1093/cid/cit370.
8. Fosnacht K, Sarraf S, Howe E, et al. How important are high response rates for college surveys? Paper presented at the Annual Forum of the Association for Institutional Research, Long Beach, CA, 2013 [cited 2016 Mar 1]. Available from: http://education.indiana.edu/ dotnetforms/Profile.aspx?u=ssarraf.

9. Cotta MO, Robertson MS, Tacey M, et al. Attitudes towards antimicrobial stewardship: results from a large private hospital in Australia. Healthcare infection 2014 [cited 2016 Mar 1];19(3):89-94. Available from: http://dx.doi.org/10.1071/HI14008.

10. Abera B, Kibret M, Mulu W. Knowledge and beliefs on antimicrobial resistance among physicians and nurses in hospitals in Amhara Region, Ethiopia. BMC Pharmacol Toxicol. 2014 [cited 2016 Mar 1];15(1):26. Available from: http://www.biomedcentral.com/2050$6511 / 15 / 26$.

11. Navarro-San Francisco CN, Del Toro MD, Cobo J, et al. Knowledge and perceptions of junior and senior Spanish resident doctors about antibiotic use and resistance: results of a multicenter survey. Enferm Infecc Microbiol Clin 2013 Apr;31(4):199-204. doi:10.1016/j. eimc.2012.05.016.

12. Pulcini $C$, Williams $F$, Molinari $N$, et al. Junior doctors' knowledge and perceptions of antibiotic resistance and prescribing: a survey in France and Scotland. Clin Microbiol Infect. 2011;17:80-87. doi:10.1111/j.1469-0691.2010.03179.x.

13. South African Pharmacy Council (SAPC). Good pharmacy practice in South Africa. 4th ed. Pretoria: SAPC; 2010.

14. Republic of South Africa. Medicines and Related Substances Act (Act 101 of 1965, as amended) [cited 2016 Mar 1]. Pretoria: Government Printer. Available from: http://www.hpcsa.co.za/Uploads/editor/ UserFiles/downloads/legislations/acts/medicines_and_related_sub_ act_101_of_1965.pdf.

15. Minen MT, Duquaine D, Marx MA, et al. A survey of knowledge, attitudes, and beliefs of medical students concerning antimicrobial use and resistance. Microb Drug Resist. 2010;16:285-9.

Received: 01-12-2015 Accepted: 19-05-2016 